\title{
Current Understanding of Microstructure and Properties of Micro-Alloyed Low Carbon Steels Strengthened by Interphase Precipitation of Nano-Sized Alloy Carbides: A Review
}

\author{
Y.-J. ZHANG ${ }^{10},{ }^{1,5}$ E. CHANDIRAN, ${ }^{1}$ H.-K. DONG, ${ }^{2}$ N. KAMIKAWA, ${ }^{3}$ \\ G. MIYAMOTO, ${ }^{1,4}$ and T. FURUHARA ${ }^{1}$ \\ 1.-Institute for Materials Research, Tohoku University, 2-1-1 Katahira, Aoba-ku, Sendai 980- \\ 8577, Japan. 2.-Key Laboratory of Advanced Materials of Ministry of Education, School of \\ Materials Science and Engineering, Tsinghua University, Beijing 100084, China. 3.—Department \\ of Mechanical Science and Engineering, Graduate School of Science and Technology, Hirosaki \\ University, Hirosaki 036-8561, Japan. 4.--Research Center for Structural Materials, National \\ Institute for Materials Science (NIMS), 1-2-1 Sengen, Tsukuba 305-0047, Japan. \\ 5.—e-mail: yongjie@imr.tohoku.ac.jp
}

The current understanding of the microstructural features and mechanical properties of micro-alloyed low carbon steels strengthened by interphase precipitation of nano-sized alloy carbides are critically reviewed in this paper. The experimental results obtained via advanced quantitative characterization have revealed that interphase precipitation is promoted at the ferrite/ austenite interface with a relatively lower degree of coherency caused by the deviation from the exact Kurdjumov-Sachs orientation relationship. Its dispersion becomes refined by enlarging the driving force for its precipitation, as adjusted by changing the transformation condition and chemical composition. The occurrence of interphase precipitation can significantly increase the strength of steels due to its large precipitation strengthening, and maintain good ductility as a result of enhanced work-hardening and dynamic recovery in different stages of tensile deformation. Finally, the application of interphase precipitation to ferrite/martensite dual-phase steels, together with our outlook on the challenging points in future research, are briefly explained.

\section{INTRODUCTION}

Modern steels for structural applications are required to have high strength to satisfy the social demands for weight-saving and downsizing of structural parts without degradation in performance. In principle, the strength of steels can be tuned by the microstructural control of various factors, i.e., solidsolution strengthening, grain boundary strengthening, precipitation strengthening, and dislocation strengthening, where the strengthening induced by precipitation of second-phase particles is known

(Received June 14, 2021; accepted August 30, 2021;

published online September 28, 2021) to be the most effective way to obtain a large amount of strengthening.

If the slip deformation is resisted by the resistive force of precipitates, the critical resolved shear stress required for dislocations to either cut through or pass between the particles should be influenced by the volume fraction of the precipitates. In the condition of a certain volume fraction, the relationship between the amount of precipitation strengthening and the particle size can be schematically illustrated (Fig. 1). The particles with a small size will be easily sheared by the dislocation movement and the resultant contribution to strength becomes larger with the increment in particle size, which is known as the "cutting mechanism." In contrast, when the particle size is sufficiently large, dislocations can hardly penetrate the particles but bypass 


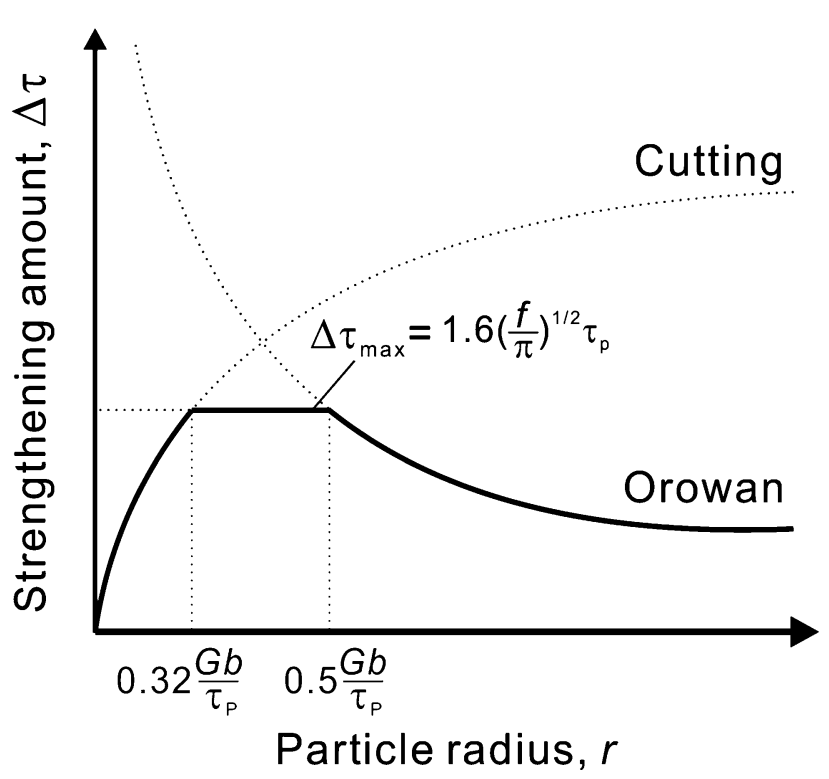

Fig. 1. Schematic of the relationship between the amount of precipitation strengthening and particle radius. $f$ volume fraction, $G$ shear modulus, $b$ magnitude of Burgers vector, $\tau_{P}$ friction stress of particle.

them instead, resulting in a strengthening amount inversely related to the particle size, which is known as the "Orowan mechanism." One of the strategies to obtain a larger amount of precipitation strengthening is to simply enlarge the volume fraction of the precipitates, which generally requires a large quantity of alloying additions and thus increases the cost of steel production. An alternative way is to refine the size of the precipitates as much as possible in the region where the Orowan bypass mechanism works, until reaching the plateau of a maximum precipitation strengthening, for which the critical particle size corresponding to the transition of these two strengthening mechanisms is basically determined by the resistive force of the precipitates, as shown in Fig. 1. This can be realized by microalloying additions of strong carbide-forming elements, where nano-sized NaCl-type (B1 structure) alloy carbides are formed with a large amount of precipitation strengthening. For example, in the work by the research group of the present authors, ${ }^{3}$ the continuous increment in strengthening amount with the reduction in particle size indicates that the critical radius is even smaller than $2 \mathrm{~nm}$ due to its hard nature, and thus suggests the possibility of obtaining an even larger amount of precipitation strengthening by further refining the particle size via the optimization of alloy design and processing conditions.

Generally, the precipitation of nano-sized alloy carbides in steels can be obtained in two distinctive ways. One is the tempering of martensitic or bainitic steels supersaturated with $\mathrm{C}$ and carbideforming elements, ${ }^{4}$ analogous to the common aging process in other metallic materials. The other one is the application of interphase precipitation, which occurs during austenite $(\gamma)$ to ferrite $(\alpha)$ transformation in micro-alloyed steels with strong carbideforming elements such as $\mathrm{V}, \mathrm{Nb}, \mathrm{Ti}, \mathrm{Mo}$, etc. Due to much lower solubility of these elements in $\alpha$ than in $\gamma,{ }^{5}$ alloy carbides are periodically nucleated at the migrating $\alpha / \gamma$ interface in a sheet manner. ${ }^{6}$ When the $\alpha / \gamma$ interface advances with the progression of $\alpha$ growth, the previously formed alloy carbides, usually exhibiting a single variant, will be left in the $\alpha$ matrix and thus contribute to the strength. One typical example of B1-type alloy carbides (MC) formed by interphase precipitation observed by our group is shown in Fig. 2 . The high-resolution image in Fig. 2b clearly shows the disk shape of the VC precipitates with a habit plane parallel to $(001) \alpha$, and the diffractogram in Fig. 2c demonstrates the Baker-Nutting orientation relationship (B-N OR, $\left.(100) \alpha / /(100)_{\mathrm{MC}},[001] \alpha / /[01 \overline{1}]_{\mathrm{MC}}\right)$ between the matrix and the precipitates. ${ }^{7}$ Compared with the aging precipitation, the advantage of interphase precipitation lies in the fact that it occurs even in continuous cooling in steel processing, and hence no further time and cost-consuming tempering process is necessary. Since the development of steel sheet with the multiple addition of $\mathrm{Ti}$ and Mo, named NANOHITEN ${ }^{\mathrm{TM}}$ (new application of nanoobstacles for dislocation movement) by the JFE company, the steels strengthened by interphase precipitation of alloy carbides, characterized by a combination of high strength and excellent holeexpanding property, have already been commercialized and widely used, especially for automobiles, ${ }^{8}$ and have attracted increasing research interest in the past decade. ${ }^{9-20}$

Interphase precipitation was first discovered in the $1960 \mathrm{~s},{ }^{21}$ and has been observed in steels with various alloying additions of $\mathrm{Cr},{ }^{22} \mathrm{Mo},{ }^{23-25} \mathrm{Nb},{ }^{26,27}$ $\mathrm{Ti}^{28}$ or $\mathrm{V},{ }^{29-32}$ among which the nano-sized alloy carbides formed in $\mathrm{Nb}-$, Ti-, or $\mathrm{V}$-added steels show relatively larger amounts of precipitation strengthening than the others. Since its discovery, many efforts have been made to understand the nature of interphase precipitation, especially its formation mechanism. As interphase precipitation occurs at the migrating $\alpha / \gamma$ interface, it should be strongly affected by the interphase boundary characters. The typical distribution of interphase precipitation in planar sheets implies the existence of some crystallographic constraints. By referencing the ledgewise growth of $\alpha,{ }^{33}$ Honeycombe ${ }^{5}$ proposed a pioneering ledge model which is schematically illustrated in Fig. 3a. In his model, the Kurdjumov-Sachs orientation relationship (K-S OR, (111) $\gamma / /(011) \alpha,[101] \gamma / /$ $[\overline{11} 1] \alpha)$ is a prerequisite condition, and the alloy carbides are suggested to be nucleated only on highly coherent immobile terrace planes (assumed to be the close packed planes of $(011) \alpha / /(111) \gamma)$, where enough time can be obtained for nucleation. Since $\alpha$ growth is proceeded by the lateral migration 

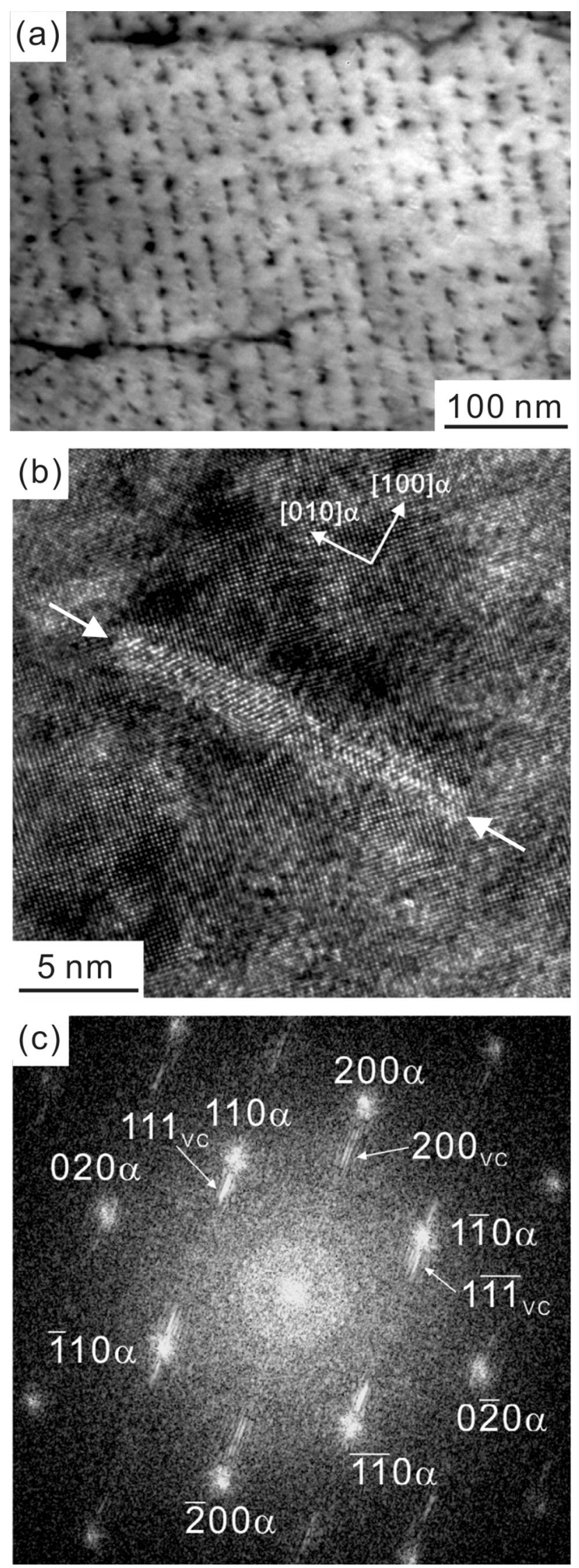

Fig. 2. (a) Bright-field TEM image, (b) high-resolution TEM image, and (c) corresponding diffractogram obtained by FFT of VC interphase precipitation. [Reprinted with permission from Ref. 7].

of incoherent mobile risers and the nucleation of new ledges, alloy carbides are arranged in planar sheets parallel to the close-packed terrace planes. However, this model cannot explain the curved distribution of interphase precipitation which is also frequently observed in experiments. Later, Ricks and Howell ${ }^{34}$ proposed a quasi-ledge model (schematic shown in Fig. 3b). The difference from the original ledge model is that it is not necessary for $\alpha$ and $\gamma$ to hold any rational OR, and thus the $\alpha / \gamma$ interface is disordered with a relatively lower degree of coherency and a higher mobility. Unlike the simple ledgewise growth, $\alpha$ grows via the bowing-out of the $\alpha / \gamma$ interface and is then pinned and immobilized by the subsequently precipitated alloy carbides at the bulged interface, leading to further lateral growth. The repetition of bowing and pinning processes causes alloy carbides to be formed in curved sheets without any specific sheet plane, or even in a random manner in some special cases. ${ }^{35}$ The validity of ledge and quasi-ledge models has been examined by many researchers based on the OR analysis through TEM observations, whereas the occurrence of interphase precipitation on the $\alpha / \gamma$ interfaces with K-S ${ }^{22}$ and without K-S OR ${ }^{36}$ have been reported. Recently, the sheet planes of planar $\mathrm{VC},{ }^{37} \mathrm{NbC}^{38}$ and $\mathrm{TiC}^{39}$ interphase precipitation were found to be non-unique and to largely deviate from the one predicted by the ledge model, which cannot be explained by either of the above models.

In order to make better use of interphase precipitation by microstructural control of the dispersion of alloy carbides, the effects of $\alpha$ growth rate and driving force for interphase precipitation have also been widely studied, which can be adjusted by changing the chemical composition and transformation temperature. Sakuma and Honeycombe ${ }^{26}$ used a $\mathrm{Nb}$-added low carbon steel to study the influence of transformation temperature, and reported that $\mathrm{NbC}$ interphase precipitation does not occur at relatively higher temperatures because of insufficient driving force. Batte and Honeycombe 29,30 investigated a series of $\mathrm{V}$-added steels and claimed that finer inter-sheet spacing and size of VC interphase precipitation can be obtained via increasing the bulk $\mathrm{C}$ and $\mathrm{V}$ contents or decreasing the transformation temperature, due to the increment in driving force for precipitation. These results are also supported by recent works on $\mathrm{V}$-added medium carbon steels, ${ }^{37} \mathrm{Nb}$-added, ${ }^{38}$ and Ti-added ${ }^{39}$ low carbon steels, although the magnitude of the driving force has not been quantitatively evaluated in the literature. On the other hand, the absence of $\mathrm{NbC}$ interphase precipitation at relatively lower temperatures in the study by Sakuma and Honeycombe ${ }^{26}$ 
(a)

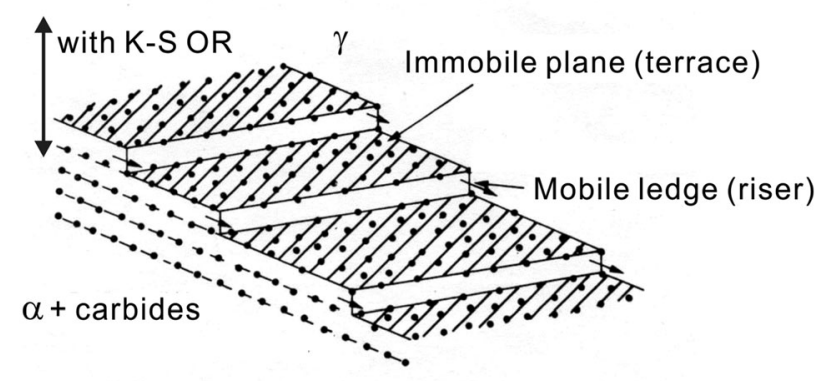

(b)

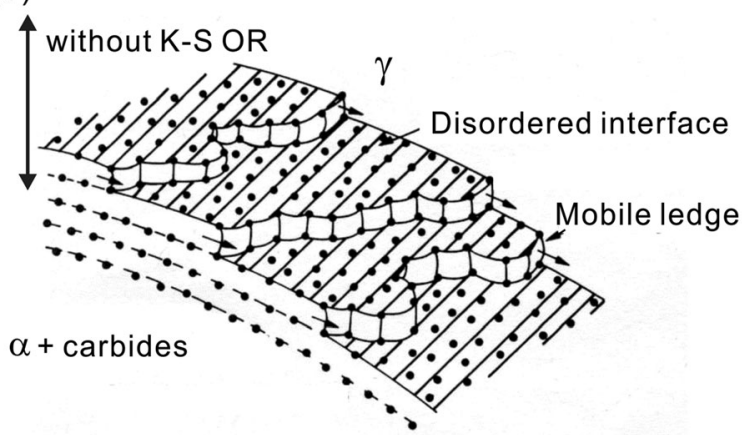

Fig. 3. Schematic of (a) ledge model and (b) quasi-ledge model proposed for interphase precipitation. [Reprinted with permission from Ref. 34]. K-S OR Kurdjumov-Sachs orientation relationship, (111) $\gamma / /(011) \alpha,[\overline{101}] \gamma / /[\overline{111}] \alpha$.

was attributed to the suppressed nucleation of alloy carbides by too fast $\alpha$ growth rate, although the driving force for precipitation becomes even larger. In another of their works, the inter-sheet spacing of $\mathrm{NbC}$ was found to be larger with the retardation of $\alpha$ growth caused by the addition of $\mathrm{Mn}{ }^{27}$ Similarly, Zajac et al. $^{40}$ also reported that the inter-sheet spacing of $\mathrm{V}(\mathrm{C}, \mathrm{N})$ interphase precipitation becomes coarser by increasing the bulk $\mathrm{C}$ content due to a lowered $\alpha$ growth rate. In contrast, the inter-sheet spacing of VC interphase precipitation formed in a V-added medium carbon steel was found to be gradually refined during the growth of $\alpha$ by Murakami et al., ${ }^{41}$ presumably because of the severer dynamic segregation of $\mathrm{V}$ at the migrating $\alpha / \gamma$ interface when the $\alpha$ growth rate becomes lower caused by $\mathrm{C}$ enrichment into $\gamma$. In other words, the influence of the $\alpha$ growth rate on the dispersion of interphase precipitation is still questionable and remains to be clarified by more elaborate works.

In addition to the experimental investigations, many numerical models have also been proposed to simulate the interphase precipitation and predict the reaction kinetics and resultant dispersion of alloy carbides. Davenport and Honecycombe ${ }^{42}$ originally proposed that the formation of alloy carbides at the $\alpha / \gamma$ interface is caused by $\mathrm{C}$ partitioning into $\gamma$ ahead of the migrating interface. Later, the local enrichment of $\mathrm{C}^{43}$ or carbide-forming elements ${ }^{44,45}$ at the $\alpha / \gamma$ interface was supposed to be the factor inducing the nucleation of subsequent sheets of interphase precipitation, which further determines the inter-sheet spacing. ${ }^{46}$ After that, models taking the ledge structures into account were developed, whereas the volume diffusion of carbide-forming elements in $\alpha^{47}$ and interfacial diffusion along the riser $^{48}$ were considered to be the rate-controlling processes. Recently, Okamoto and Agren ${ }^{49}$ established a more physical model that simultaneously considers the complex interaction between interphase precipitation and solute segregation at the migrating $\alpha / \gamma$ interface from a viewpoint of energy dissipation, ${ }^{50}$ which can well reproduce the intersheet spacing and the size of $\mathrm{NbC}$ interphase precipitation in a $\mathrm{Nb}$-added low carbon steel.

It can be readily noted that most of the previous works mainly focused on the inter-sheet spacing, as it is the typical microstructural characteristic of interphase precipitation. However, our group recently reported that the inter-particle spacing in each sheet of VC interphase precipitation is close to its inter-sheet spacing. ${ }^{7}$ It can thus be deduced that, rather than inter-sheet spacing, the three-dimensional dispersion of nano-sized alloy carbides is more important in determining the amount of strengthening by interphase precipitation. Hence, more attention should be paid to the number density and size of nano-sized alloy carbides formed by interphase precipitation.

The current issues of interphase precipitation have been summarized above. Since more than 10 years ago, our research group has been dedicated to the experimental investigations on the microstructural evolutions and resultant mechanical properties of micro-alloyed low carbon steels strengthened by interphase precipitation of nano-sized alloy carbides, via the combination of various advanced analytical techniques such as scanning electron microscopy (SEM), electron backscatter diffraction (EBSD), nanoindentation, digital image correlation (DIC), transmission electron microscopy (TEM) and three-dimensional atom probe (3DAP). In this review, the critical findings in our previous studies on interphase precipitation will be introduced, and the future outlook will also be briefly described.

\section{MICROSTRUCTURAL CHARACTERISTICS OF INTERPHASE PRECIPITATION}

\section{Effects of $\alpha / \gamma$ Orientation Relationship on the Dispersion of Interphase Precipitation}

The morphology of proeutectoid $\alpha$ nucleated at the $\gamma$ grain boundary is known to change with the transformation temperature. Allotriomorphic and idiomorphic grain boundary $\alpha$ (GBF) are predominantly formed at relatively higher temperatures, whereas lowering the transformation temperature induces the morphology to be changed into Widmanstatten $\alpha$ (WF) owing to the larger driving force for $\alpha$ transformation. ${ }^{51}$ Figure $4 \mathrm{a}$ shows the $\alpha$ orientation map of a V-added low carbon steel (Fe$0.1 \mathrm{C}-1.5 \mathrm{Mn}-0.4 \mathrm{~V}$ alloy; all the numbers are in 


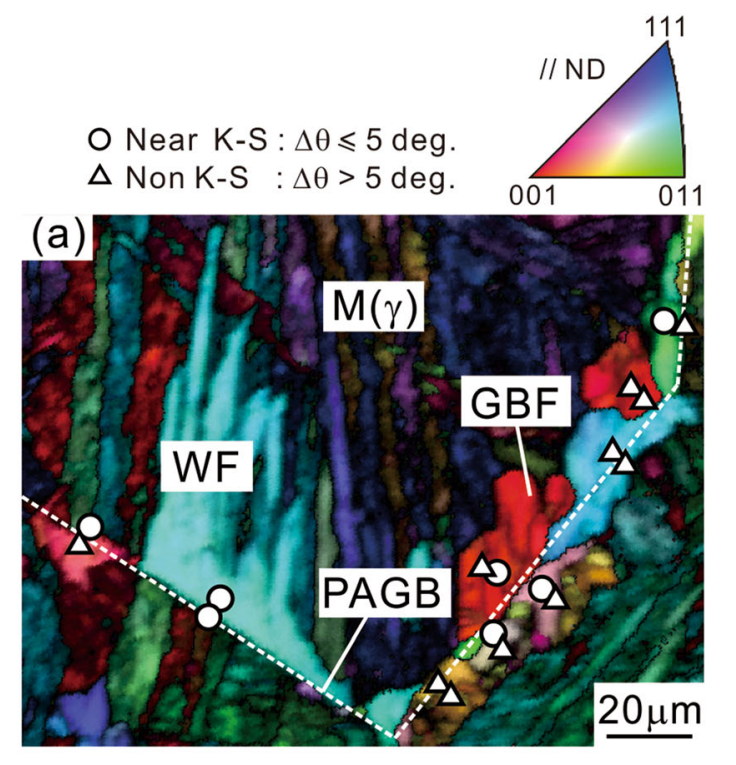

(b) WF $(\Delta \theta=0.8$ deg. $)$

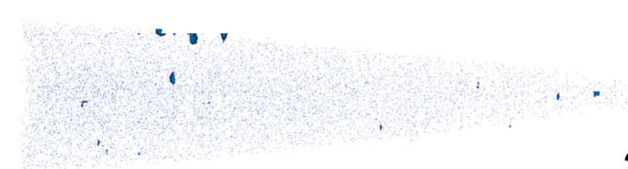

$\underline{20 \mathrm{~nm}}$

(c) $\operatorname{GBF}(\Delta \theta=19.2$ deg. $)$

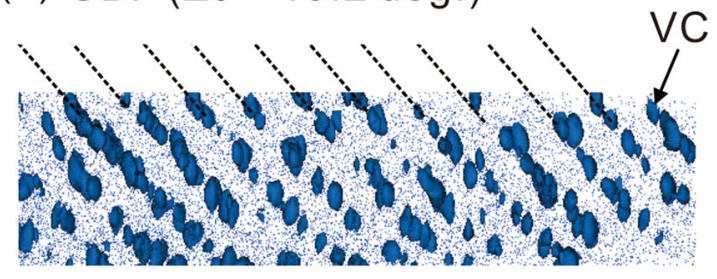

$\underline{20 \mathrm{~nm}}$ (d)

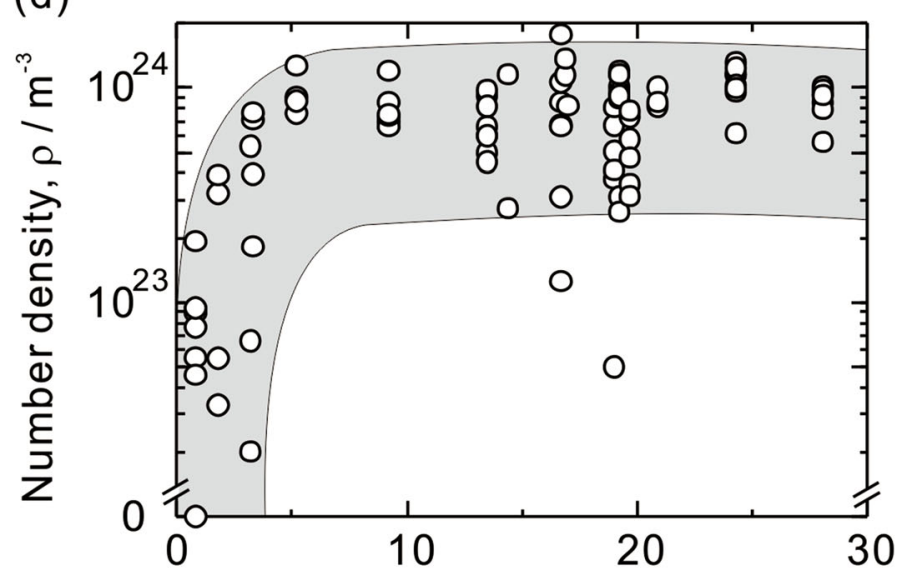

(e)

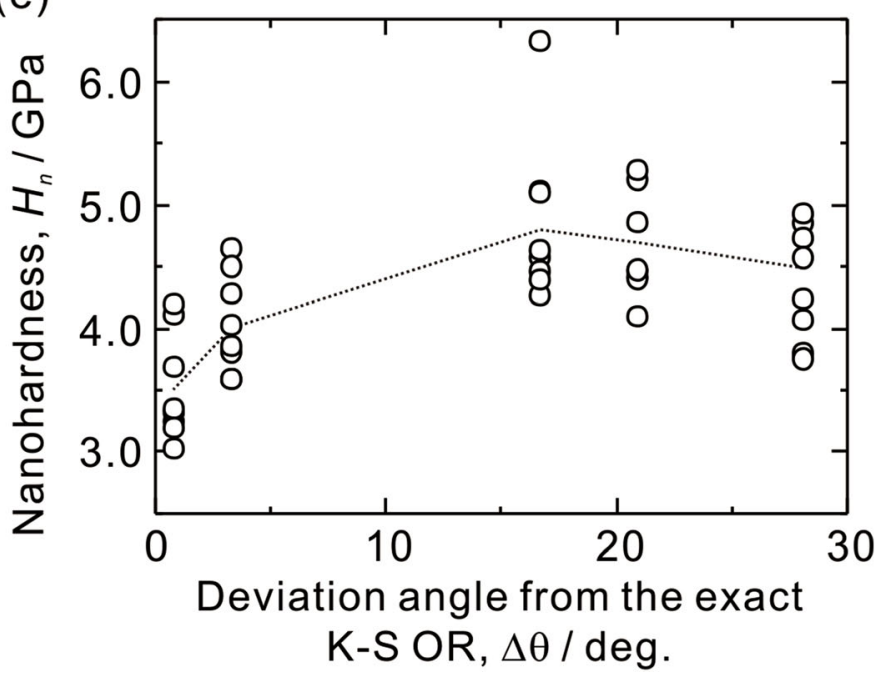

Fig. 4. (a) $\alpha$ orientation map superimposed by image quality map of an Fe- $0.1 \mathrm{C}-1.5 \mathrm{Mn}-0.4 \mathrm{~V}$ alloy partially transformed at $923 \mathrm{~K}$, with threedimensional $\mathrm{V}$ atom maps superimposed by 2 at\% V iso-concentration surfaces corresponding to (b) WF and (c) GBF; [reprinted with permission from Ref. 52], and variations in (d) number density of VC precipitates and (e) nanohardness of $\alpha$ with $\Delta \theta$, [reprinted from Ref. 56]. WF Widmanstatten $\alpha$; GBF grain boundary $\alpha$; PAGB prior $\gamma$ grain boundary; $M(\gamma)$ martensite formed from $\gamma$ during quenching; $\Delta \theta$ deviation angle from the exact K-S OR.

mass\% unless otherwise specified) partially transformed at an intermediate temperature, with the mixed structures of both $\mathrm{WF}$ and $\mathrm{GBF}^{52}$ The orientation of prior $\gamma$ was reconstructed from those of martensite measured by EBSD, ${ }^{53}$ and used to analyze the $\alpha / \gamma$ OR. Circles and triangles shown in Fig. 4a indicate whether the $\alpha$ grains formed at the $\gamma$ grain boundary have a near K-S OR (defined as the deviation angle from the exact K-S OR $(\Delta \theta) \leqq 5^{\circ}$ ) or a non-K-S OR $\left(\Delta \theta>5^{\circ}\right)$, respectively, with the adjacent $\gamma$ grains on each side. It can be clearly seen that both GBF and WF tend to hold a near K-S OR with at least one of the two adjacent $\gamma$ grains. WF only grows into $\gamma$ grains with a near K-S OR, while GBF tends to grow by the migration of $\alpha / \gamma$ interface with an irrational non-K-S OR, which is consistent with the previous reports of low carbon steels without microalloying additions. ${ }^{54,55}$ Site-specific specimen preparation for 3DAP analysis was then performed by focused ion beam, for which the typical three-dimensional $\mathrm{V}$ atom maps superimposed by its iso-concentration surfaces corresponding to WF and GBF are shown in Fig. $4 \mathrm{~b}$ and c, respectively. Almost no VC precipitate is formed in the WF holding a near K-S OR $\left(\Delta \theta=0.8^{\circ}\right)$, whereas a high density of VC interphase precipitation distributed in planar sheets can be observed in the GBF holding a non-K-S OR $\left(\Delta \theta=19.2^{\circ}\right) .^{52}$ After analyzing numbers of $\alpha$ grains with various ORs, the dependence of number density of VC interphase 
precipitation on $\Delta \theta$ is summarized in Fig. $4 d$, where each point corresponds to the data analyzed from a single 3DAP dataset. As the $\alpha / \gamma$ OR deviates from the exact $\mathrm{K}-\mathrm{S}$ one, the number density of $\mathrm{VC}$ precipitates are significantly increased at $\Delta \theta$ smaller than $5^{\circ}$, until reaching a plateau at $\Delta \theta$ larger than $5^{\circ}$. In contrast, the size of $\mathrm{VC}$ precipitates is found to be only slightly influenced by $\alpha / \gamma$ OR. ${ }^{52}$ As a result, the nanohardness of $\alpha$ strengthened by VC precipitates (Fig. 4e) shows the same tendency as that in number density, indicating that higher hardness of $\alpha$ can be obtained by more dispersed VC interphase precipitation. ${ }^{56}$ It should be mentioned that these data also include some cases of GBF holding a near K-S OR, which means that the dispersion of interphase precipitation and resultant hardening effects are actually determined by $\alpha / \gamma$ OR rather than by the morphology of $\alpha$. The occurrence of interphase precipitation in planar sheets at the $\alpha /$ $\gamma$ interface with a non-K-S OR suggests that, even when the $\alpha / \gamma$ OR largely deviates from the rational K-S OR, the macroscopic $\alpha / \gamma$ interface should be composed of some partially coherent crystal planes in local regions, the mobility of which is sufficiently low to enable the nucleation of alloy carbides at the interface, ${ }^{57}$ whereas, in some special cases when the degree of coherency is not sufficiently low, irregular or even random dispersion of alloy carbides rather than planar sheets might also be formed. ${ }^{39,52}$ Similar results were also observed in a $\mathrm{V}$-added medium carbon steel, and the ledge model extended to the non-K-S $\alpha / \gamma$ interface should be more applicable to explain the formation of interphase precipitation in the real case. ${ }^{37}$ On the other hand, the variation in number density shown in Fig. $4 \mathrm{~d}$ for the first time ever quantitatively reveals the suppressed nucleation of alloy carbides at the $\alpha / \gamma$ interface with a near K-S OR. This result suggests that, even though partially coherent planes might exist at a non-K-S $\alpha /$ $\gamma$ interface, the interfacial coherency of the near K-S $\alpha / \gamma$ interface is still relatively higher, ${ }^{58}$ which has a large influence on the resultant interphase precipitation behaviors.

By further performing delicate 3DAP compositional analysis of the regions in the vicinity of the $\alpha /$ $\gamma$ interface, it was experimentally confirmed that strong carbide-forming elements such as $\mathrm{V},{ }^{59} \mathrm{Nb},{ }^{60}$ and $\mathrm{Mo}^{61}$ are severely segregated at the migrating non-K-S $\alpha / \gamma$ interface, but absent at the highly coherent near K-S interface. Such dynamic segregation should be the main reason for the accelerated carbide nucleation kinetics at the less coherent non$\mathrm{K}-\mathrm{S}$ interface. One example of our recent work on a $\mathrm{Nb}$-added low carbon steel is shown in Fig. $5 .{ }^{62}$ The maps shown in Fig. 5b and c correspond to the projected view of the non-K-S $\alpha / \gamma$ interface indicated in Fig. 5a, where the $\mathrm{Nb}$ clusters indicated by arrows might be formed via phase separation, e.g., by spinodal fluctuations inside the segregated interface as a result of strong attractive interaction between $\mathrm{Nb}$ and $\mathrm{C},{ }^{63}$ and act as the precursors for (a)

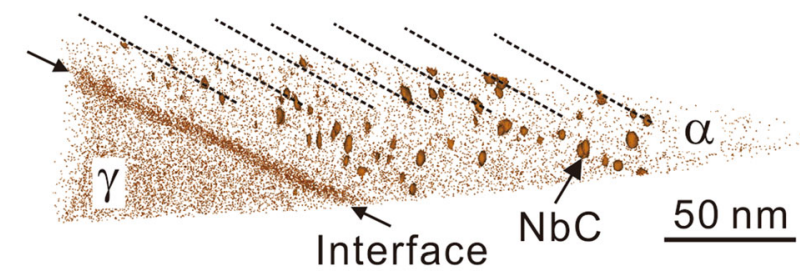

(b)

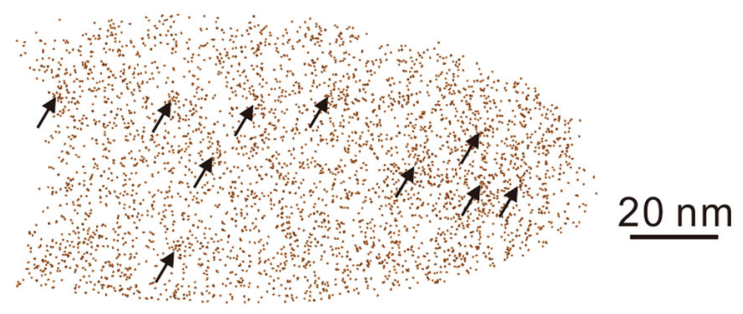

(c)

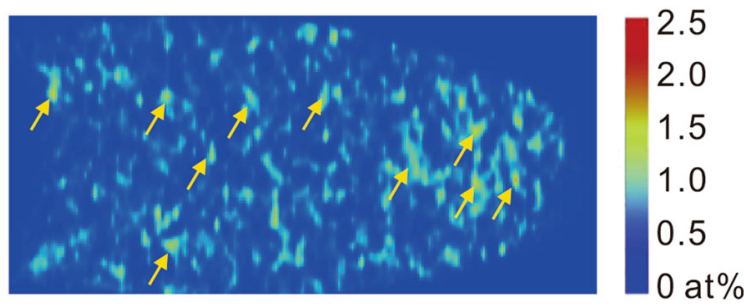

Fig. 5. (a) Three-dimensional $\mathrm{Nb}$ atom map superimposed by 1.5 at\% $\mathrm{Nb}$ iso-concentration surfaces in an Fe-0.1C-0.06 Nb alloy transformed at $1023 \mathrm{~K}$, with (b) Nb atom map, and (c) twodimensional contour plot of $\mathrm{Nb}$ concentration of $\alpha / \gamma$ interface sliced with a thickness of $8 \mathrm{~nm}$; [reprinted from Ref. 62].

the subsequent formation of alloy carbides. This result directly demonstrates the coupling between precipitation and solute segregation at the $\alpha / \gamma$ interface, which should be the mainstream for research on interphase precipitation in the near future.

\section{Effects of Transformation Temperature and Chemical Composition on the Dispersion of Interphase Precipitation}

Since interphase precipitation occurs at the migrating $\alpha / \gamma$ interface, the interphase boundary characters such as the $\alpha$ growth rate and driving force for precipitation should have a strong influence on the dispersion of interphase precipitation. The $\alpha$ growth rate is the result of the balance between element diffusivity and the degree of supersaturation for $\alpha$ transformation, while the driving force for interphase precipitation is closely related to the composition at the migrating $\alpha / \gamma$ interface during $\alpha$ transformation. Both of them are mainly determined by the $\alpha / \gamma$ phase equilibria and $\alpha$ transformation kinetics, which are strongly dependent on the transformation conditions, such as the temperature and chemical composition of steels. ${ }^{50}$ Their effects on the dispersion of alloy carbides 
formed by interphase precipitation in a series of low carbon steels micro-alloyed with $\mathrm{V}, \mathrm{Nb}$, and $\mathrm{Ti}$ were systematically investigated, with the above-mentioned influence of $\alpha / \gamma$ OR eliminated via purposely selecting GBF holding a non-K-S OR with $\gamma$ formed in various transformed alloys for comparison.

Figure $6 \mathrm{a}$ and $\mathrm{b}$ shows the temperature dependence of number density and average radius of $\mathrm{VC}$ interphase precipitation formed in the same Vadded steel as that in Fig. 4. The average values connected by the dotted lines in these figures demonstrate that the dispersion of $\mathrm{VC}$ precipitates becomes refined, i.e., higher in number density and smaller in size, by lowering the transformation temperature and thus with larger degrees of supersaturation. ${ }^{64}$ Such temperature dependence is commonly shared by other alloys transformed in this temperature range. ${ }^{65}$ Figure $6 \mathrm{c}$ and $d$ shows the variation in number density and average radius of VC interphase precipitation with the bulk V and C contents, formed at the same temperature. The number density of the VC precipitates is increased while the size is slightly refined, with the increment in the amount of $\mathrm{V}$ addition up to 0.4 mass $\%$. The comparison of the results for the $0.1 \mathrm{C}-0.4 \mathrm{~V}$ and $0.2 \mathrm{C}-0.4 \mathrm{~V}$ alloys suggest that the dispersion of the VC interphase precipitation is marginally influenced by the excessive amount of $\mathrm{C}$ against $\mathrm{V}$ in atomic fraction, and thus lower $\alpha$ growth rate due to $\mathrm{C}$ enrichment in $\gamma^{65}$ When the bulk $\mathrm{C}$ and $\mathrm{V}$ contents are further increased from $0.1 \mathrm{C}-0.4 \mathrm{~V}$ to $0.3 \mathrm{C}-1.3 \mathrm{~V}$, even more dispersed $\mathrm{VC}$ precipitates in a higher number density can be obtained as a result of the larger driving force for precipitation.

Besides the investigations on the effects of transformation temperature and bulk $\mathrm{C}$ and $\mathrm{V}$ contents, the comparison of $\mathrm{VC}, \mathrm{NbC}$, and $\mathrm{TiC}$ interphase precipitation was also performed on a series of low carbon steels with a base alloy composition of $\mathrm{Fe}-$ $0.1 \mathrm{C}-1.5 \mathrm{Mn}$ with various amounts of $\mathrm{V}, \mathrm{Nb}$, and Ti. ${ }^{66}$ Moreover, the additions of typical non-carbideforming elements in steels, e.g., $\mathrm{Mn}$ and $\mathrm{Si}$, as a typical $\gamma$-stabilizer and $\alpha$-stabilizer, respectively, were purposely adjusted to study the influence of $\alpha$ growth rate on the dispersion of the VC interphase precipitation. ${ }^{65}$ Figure 7 a shows a schematic of a
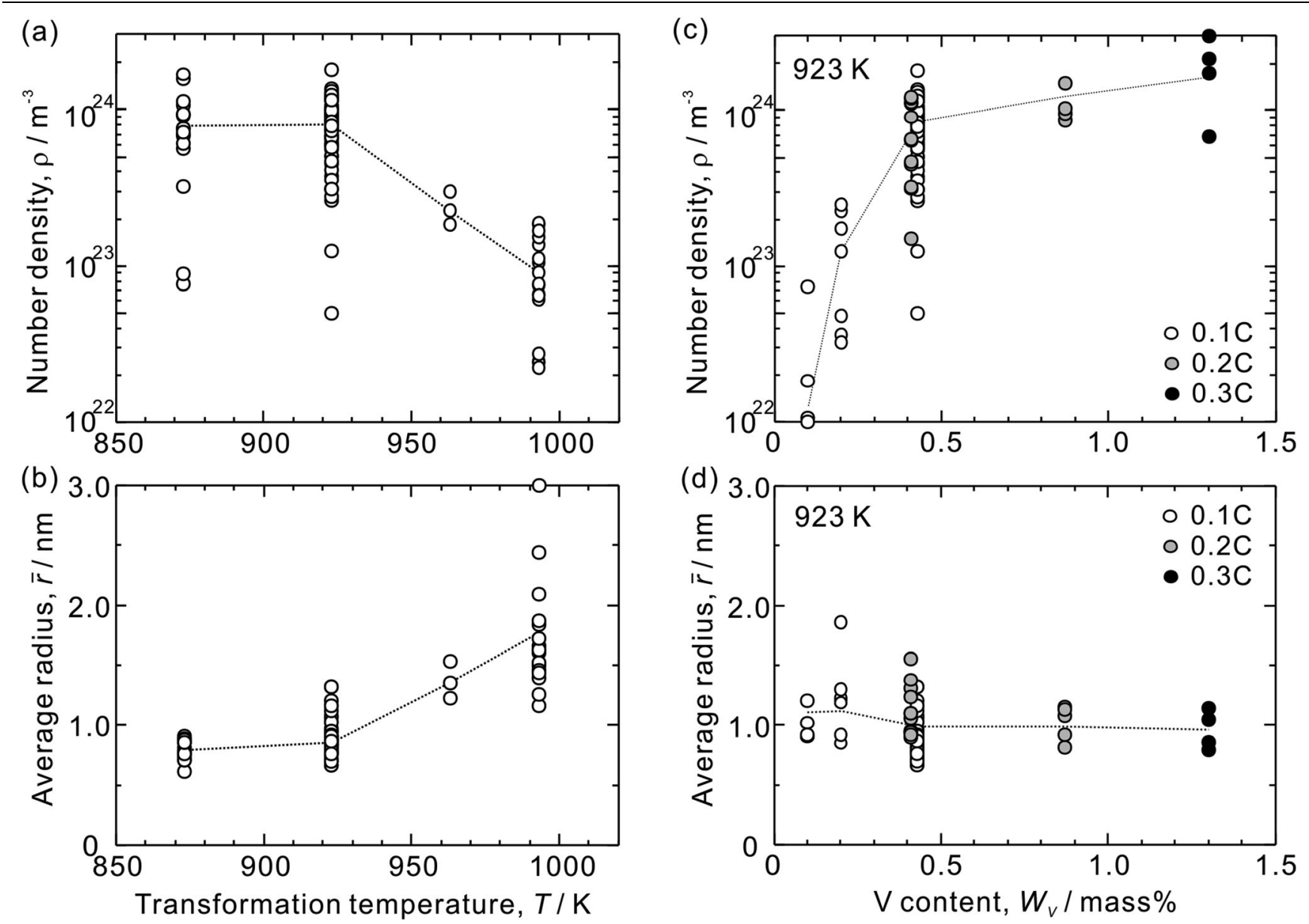

Fig. 6. Variations in number density and average radius of $\mathrm{VC}$ precipitates with $(\mathrm{a}, \mathrm{b})$ transformation temperature in an $\mathrm{Fe}-0.1 \mathrm{C}-1.5 \mathrm{Mn}-0.4 \mathrm{~V}$ alloy; [reprinted with permission from Ref. 64], and with (c, d) bulk V and C contents in a series of V-added alloys transformed at $923 \mathrm{~K}$; [reprinted with permission from Ref. 65]. 

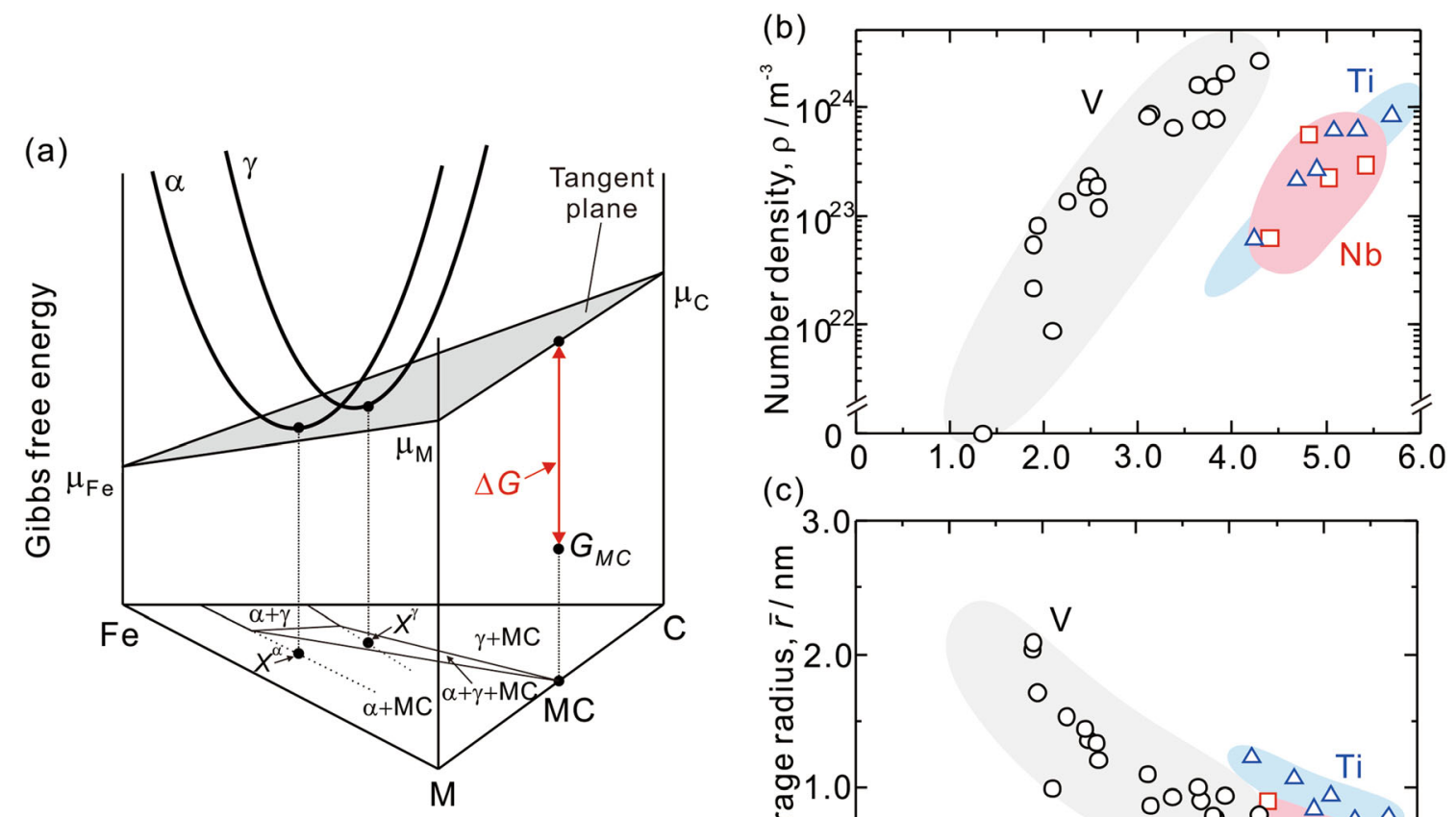

(c)

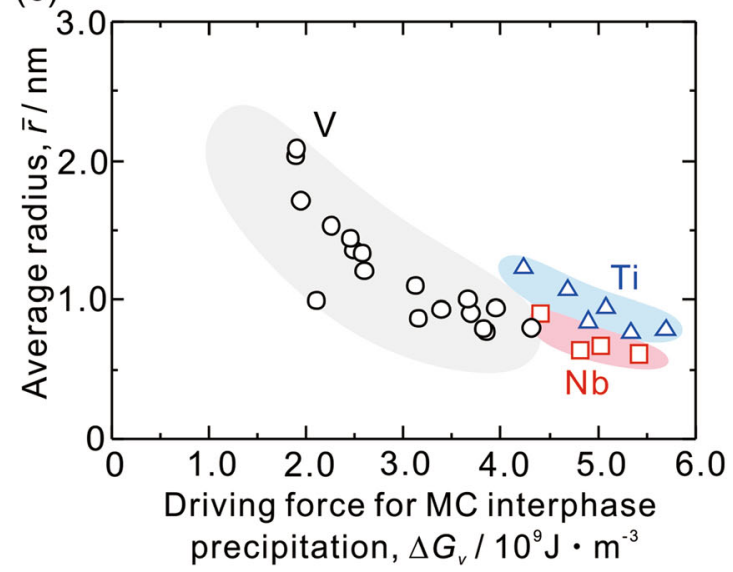

Fig. 7. (a) Schematic of driving force for MC interphase precipitation as indicated by red arrow line; [reprinted with permission from Ref. 59], with variations in (b) number density, and (c) average radius of $\mathrm{MC}$ precipitates in a series of $\mathrm{Fe}-0.1 \mathrm{C}-1.5 \mathrm{Mn}$-based alloys with $\mathrm{V}, \mathrm{Nb}$, or Ti addition. Data for $\mathrm{V}$ include the alloys with a bulk $\mathrm{V}$ content from 0.1 mass $\%$ to $1.3 \mathrm{mass} \%$, transformed in a temperature range from $993 \mathrm{~K}$ to $873 \mathrm{~K}$, while data for $\mathrm{Nb}$ and $\mathrm{Ti}$ include the alloys with bulk $\mathrm{Nb}$ and $\mathrm{Ti}$ contents up to $0.1 \mathrm{mass} \%$ and $0.2 \mathrm{mass} \%$, respectively, transformed in a temperature range from $963 \mathrm{~K}$ to $923 \mathrm{~K}$; [reprinted from Ref. 66].

Gibbs free energy diagram in an Fe-C-M ternary system as an example, where the driving force for the MC interphase precipitation is estimated. According to our quantitative measurement of $\mathrm{C}$ enrichment in $\gamma$ during $\alpha$ growth by using electron probe microanalyzer, ${ }^{59}$ the $\alpha / \gamma$ phase equilibria in $\mathrm{V}$ added steels with interphase precipitation were found to show good agreement with the prediction by negligible partitioning local equilibrium $(\mathrm{NPLE})^{67,68}$ rather than para-equilibrium (PE) ${ }^{69}$ Hence, the chemical potentials of $\mathrm{M}$ and $\mathrm{C}$ at the migrating $\alpha / \gamma$ interface before interphase precipitation are equivalent in both $\alpha$ and $\gamma$, as indicated by the common tangent plane in Fig. 7a, and the gap between the tangent plane and the free energy of MC phase represented by the arrow line is regarded as the driving force for MC interphase precipitation. ${ }^{59}$ The number density and average radius of MC interphase precipitation formed in various conditions quantified by 3DAP are plotted against the driving force calculated by using Thermo-Calc in Fig. $7 \mathrm{~b}$ and c, respectively. Although the data group for $\mathrm{V}$-added steels contains the specimens with $\alpha$ growth rate differing by more than one order of magnitude caused by the change in transformation temperature as well as the amounts of $\mathrm{Mn}$ and $\mathrm{Si}$ additions, the dispersion of VC precipitates shows quite good correlations with the calculated driving force, i.e., higher in number density and smaller in size by enlarging the driving force, which suggests that compared with the dominant influence of driving force for precipitation, the $\alpha$ growth rate, at least in the present range of magnitude, might play a minor role in determining the dispersion of interphase precipitation in low carbon steels. ${ }^{65}$ The refinement tendency in dispersion with increasing the driving force is also shared by $\mathrm{NbC}$ and $\mathrm{TiC}$ interphase precipitation, whereas the data bands of $\mathrm{Nb}$-added and Ti-added steels at much larger driving force significantly deviate from that of V-added ones, especially for the number density shown in Fig. $7 \mathrm{~b}$. When compared at the same driving force, the lower number density of $\mathrm{NbC}$ and $\mathrm{TiC}$ than VC is considered to be caused by the combined effects of their relatively smaller amounts of additions (thus, lesser volume fraction of alloy carbides) and larger $\alpha / \mathrm{MC}$ interfacial energies as the energy barrier for precipitation than the case of $\mathrm{V} .{ }^{66}$ Based on all the above results, the strategy to obtain finer dispersions of interphase precipitation with larger amounts of strengthening can be summarized as follows: (1) enlarging the driving force for 
precipitation by lowering the transformation temperature (although the formation of WF without interphase precipitation should be avoided ${ }^{52}$ ); (2) increasing the amount of $\mathrm{M}$ addition to increase the volume faction of $\mathrm{MC}$; and (3) reducing the interfacial energy between $\alpha$ and MC. One of the successful examples satisfying these requirements is the multiple addition of $\mathrm{Ti}$ and $\mathrm{Mo}$ in low carbon steels. ${ }^{8} \mathrm{In}$ that case, interphase precipitation of the weak carbide-forming element (Mo) is induced by the strong one (Ti), which further contributes to the reduction in lattice misfit and interfacial energy between $\alpha$ and alloy carbides. ${ }^{9}$ In order to explore the possibility of other element pairs feasible for multiple addition in steels strengthened by interphase precipitation, more work still needs to be done in the future.

\section{MECHANICAL PROPERTIES OF STEELS STRENGTHENED BY INTERPHASE PRECIPITATION}

\section{Contribution of Interphase Precipitation to Strength and Ductility}

The mechanical properties of steels strengthened by interphase precipitation have been studied by uniaxial tensile tests. Figure 8a shows the nominal tensile stress-strain curves of an Fe-0.1C-0.8Mn$0.2 \mathrm{Si}-0.3 \mathrm{~V}$ alloy consisting of a fully ferritic matrix with dispersed VC interphase precipitation, while the result of the bainitic counterpart is also shown in Fig. $8 \mathrm{~b}$ for reference. The stress-strain curves of these steels strengthened by nano-sized alloy carbides are characterized by a high yield ratio (yield strength divided by ultimate tensile strength) and a large elongation, especially the post-uniform (a)

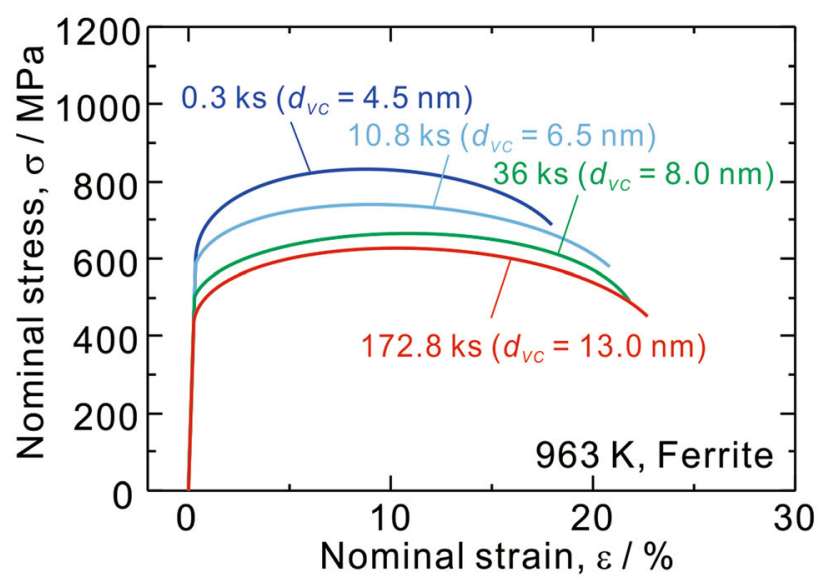

(b)

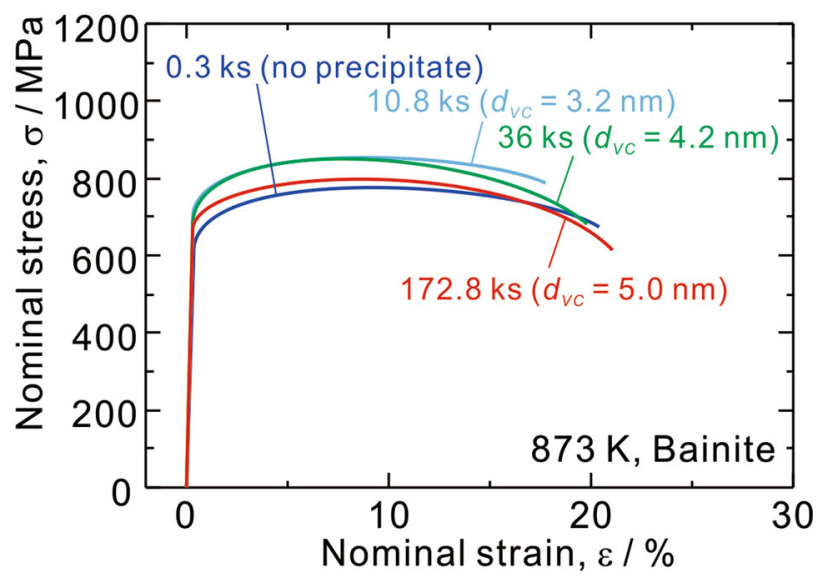

(c)

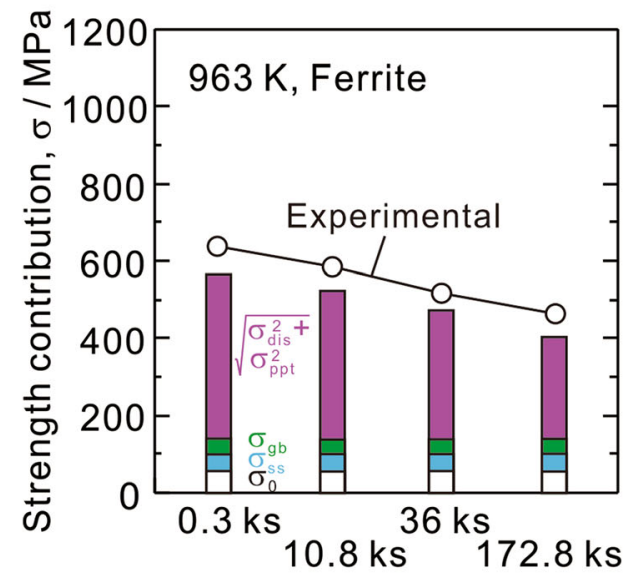

(d)

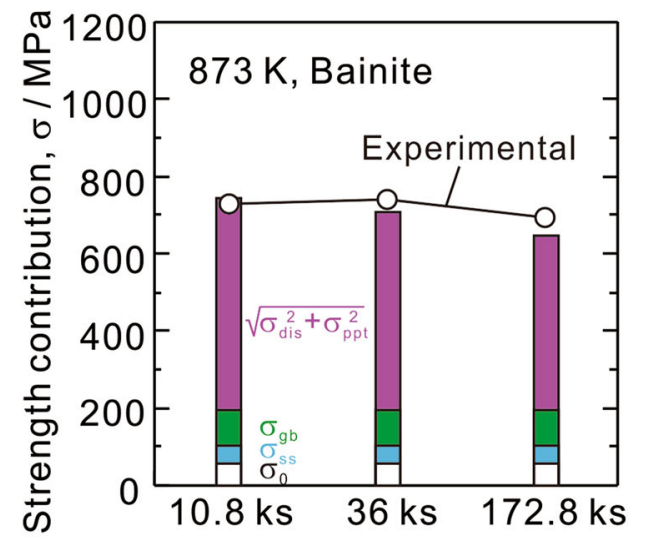

Fig. 8. Nominal stress-strain curves for an Fe-0.1C-0.8Mn-0.2Si-0.3V alloy transformed at (a) $963 \mathrm{~K}$ and (b) $873 \mathrm{~K}$, with corresponding experimentally estimated contributions of various factors to yield strength shown in (c) and (d), respectively; [reprinted with permission from Ref. 7]. $d_{V C}$ average diameter of VC precipitates, $\sigma_{O}$ friction stress, $\sigma_{s s}$ solid-solution strengthening, $\sigma_{g b}$ grain boundary strengthening, $\sigma_{d i s}$ dislocation strengthening, $\sigma_{p p t}$ precipitation strengthening. 

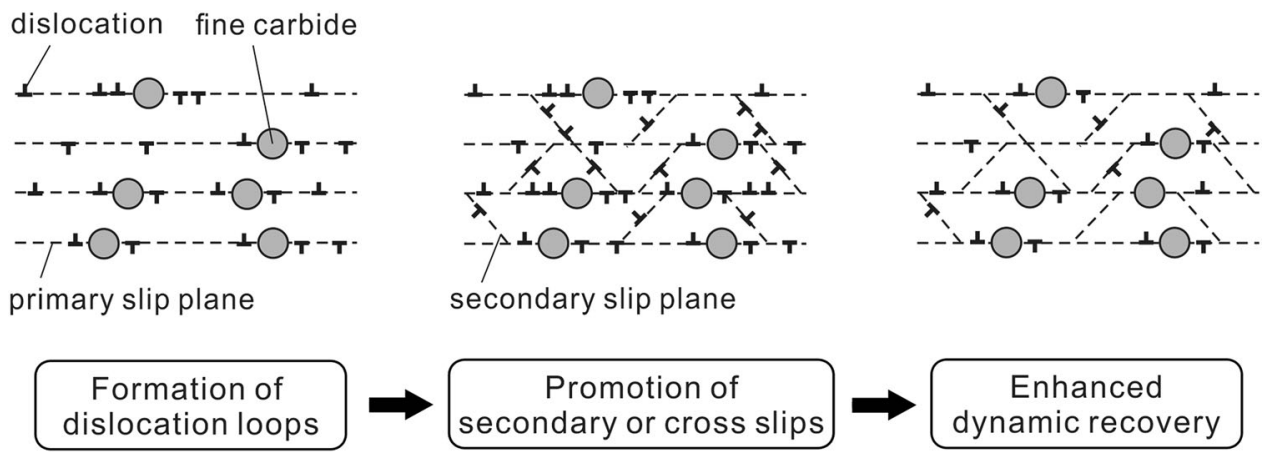

Fig. 9. Schematic of evolution in dislocation structures during deformation of specimens with a dispersion of fine carbides. [Reprinted from Ref. 3].

elongation after necking. The size of $\mathrm{VC}$ precipitates in $\alpha$ after the completion of transformation is continuously increased by increasing the isothermal holding time up to $172.8 \mathrm{ks}$, which leads to a reduction in strength due to the smaller amount of precipitation strengthening. ${ }^{7}$ In contrast, similar to the case of $\mathrm{WF}{ }^{52}$ bainite transformation proceeded only by the migration of the $\mathrm{K}-\mathrm{S}$ interface ${ }^{70}$ is initially free of any precipitates. VC precipitates are then formed from the supersaturated matrix during isothermal holding, and thus contribute to the secondary hardening. In order to discuss the contribution of interphase precipitation to strength, the microstructural features such as crystallographic grain size, dislocation density and dispersion of $\mathrm{VC}$ precipitates in both $\alpha$ and bainite were quantitatively analyzed, mainly by TEM. Our previous work on ( $\mathrm{Ti}, \mathrm{Mo}) \mathrm{C}$ interphase precipitation has revealed that the precipitation strengthening of nano-sized alloy carbides predicted by the Ashby-Orowan model, for which the interaction between dislocations with opposite signs after bowing-out from a fine particle is considered, ${ }^{2}$ is more appropriate than the conventional Orowan model to explain the experimental results. ${ }^{3}$ Hence, the evaluation of the strengthening amounts by nano-sized VC precipitates is also made here by using the Ashby-Orowan model. Figure $8 \mathrm{c}$ and $\mathrm{d}$ shows the comparison of the experimentally measured yield strength and the predicted one by considering the contributions of various strengthening factors in $\alpha$ and bainite, respectively. It was found that the simple summation of the contributions by dislocation and precipitation strengthening significantly overestimates the yield strength, whereas the Pythagorean summation ${ }^{71}$ shown in these figures shows much better agreement with the experimentally measured values. ${ }^{7}$ This is because the nano-sized alloy carbides working as the obstacles for dislocation movement have an inter-particle spacing in the same order as the spacing of dislocations. On the other hand, it can be clearly seen from Fig. 8c that the strength of $\alpha$ is mainly contributed by the combination of precipitation strengthening and dislocation strengthening. Different from bainite with a high dislocation density, strengthening by interphase precipitation of nano-sized alloy carbides plays a dominant role in determining the yield strength of $\alpha$ especially after transformation for a short time, the magnitude of which is as large as $\sim 300 \mathrm{MPa}$, again suggesting that the interphase precipitation is an effective way to strengthen ferritic steels. ${ }^{7}$

Another point worth mentioning in the tensile behaviors of the steels strengthened by nano-sized alloy carbides is their large ductility. Taking the interphase precipitation shown in Fig. 8a for example, the refinement in the dispersion of VC precipitates can increase the strength without notably reducing the elongation, in contrast to the general strength-ductility trade-off of metallic materials. Both uniform or post-uniform elongations are kept at an almost constant level, which is the typical characteristic of the steels strengthened by interphase precipitation. Based on the experimental observations by TEM, Fig. 9 shows a schematic of the evolution in dislocation structures with the presence of fine alloy carbides. ${ }^{3}$ Alloy carbides uniformly dispersed in the $\alpha$ matrix act as a strong dislocation source and further promote secondary or cross-slips, which markedly increase the work hardening rate in the initial stage of tensile deformation. The refinement in the dispersion of alloy carbides provides a higher density of sites for dislocation multiplication, and thus contributes more to the enhancement in work hardening, ${ }^{72}$ which delays the occurrence of plastic instability even at a high strength level, leading to the improvement of uniform elongation. In the later stage of tensile deformation, dislocation annihilation in the vicinity of alloy carbides occurs, and thus a finer dispersion might also enhance the dynamic recovery, consequently leading to a retarded formation of voids and cracks and the improvement of post-uniform elongation. ${ }^{7}$

\section{Application of Interphase Precipitation to Dual-Phase Steels}

The tensile properties of commercial ferritemartensite dual-phase steels are characterized by a low yield strength, a high work hardening rate, 

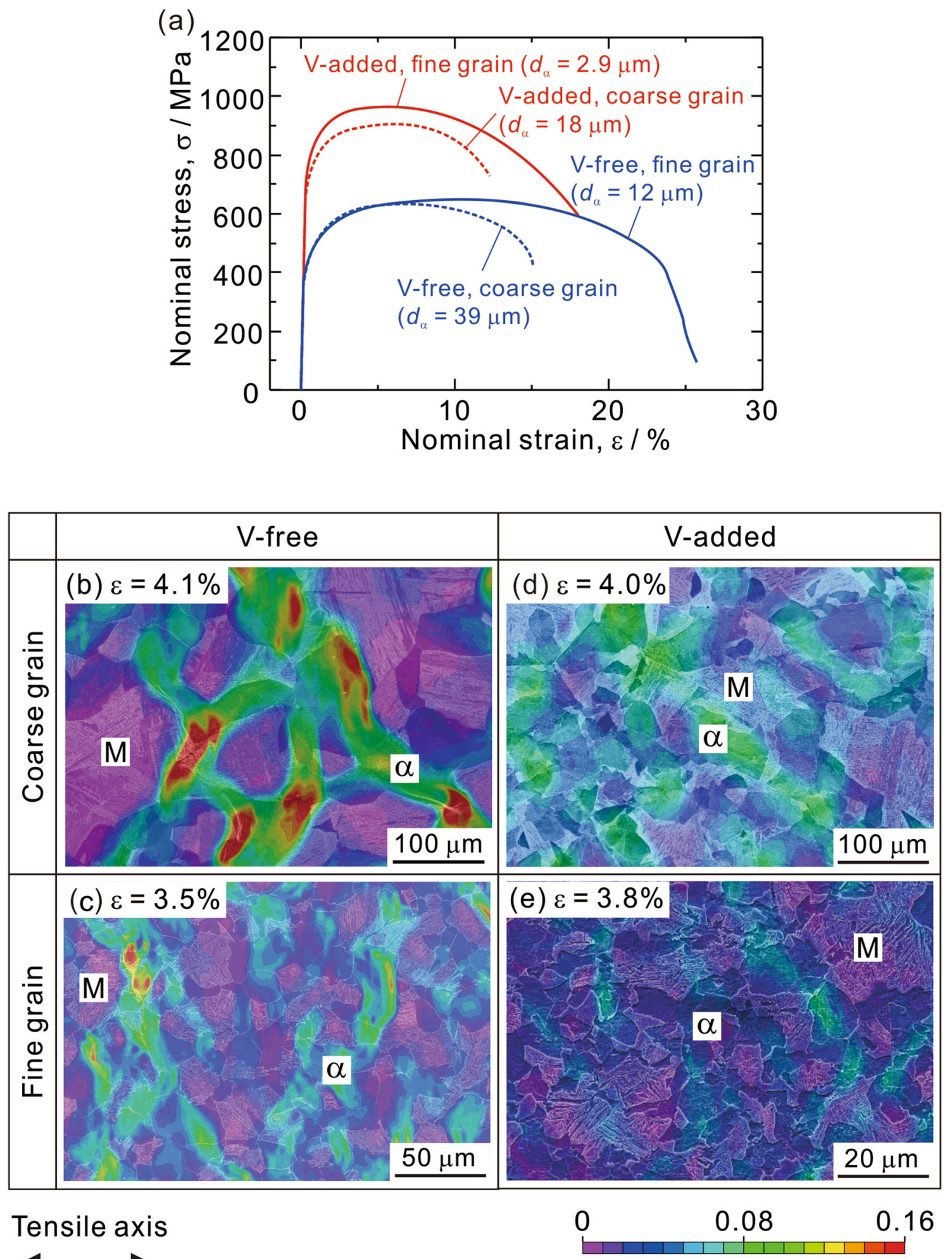

Equivalent strain

Fig. 10. (a) Nominal stress-strain curves for an Fe-0.05C-1.5Mn alloy (V-free) and an Fe-0.1C-1.5Mn-0.4V alloy (V-added) in ferrite-martensite dual-phase structures with different $\alpha$ grain sizes, with corresponding strain maps obtained by digital image correlation (DIC) shown in (b-e), respectively; [reprinted from Ref. 75]. $d_{\alpha}$ grain size of $\alpha, M$ martensite formed from $\gamma$ during quenching 
and a large uniform elongation. ${ }^{73}$ However, the drawback of these dual-phase steels is their poor post-uniform elongation caused by the large difference in strength between the ferrite and martensite phases. In contrast, as explained in the previous section, steels with a fully ferritic structure strengthened by interphase precipitation have an excellent post-uniform elongation. It is readily realized that high-strength steels with a combination of both large uniform and post-uniform elongations can be produced once the interphase precipitation of alloy carbides is applied in the dual-phase steels. The experimental results of our attempt in an Fe-0.1C-1.5Mn-0.4V alloy is summarized in Fig. 10, in which a V-free alloy was used for comparison. The transformation conditions for both alloys were adjusted to form $\alpha$ with a volume fraction of $\sim 50 \%$, together with martensite formed during quenching having the same hardness in both alloys. ${ }^{74}$ In addition, hot deformation of $\gamma$ before $\alpha$ transformation was also performed in the $\mathrm{V}$-added alloy to refine the $\alpha$ grain size, in order to clarify its influence on the tensile behaviors. ${ }^{75}$ According to the nominal stress-strain curves shown in Fig. 10a, a dual-phase steel with a high strength and large uniform and post-uniform elongations can be obtained by introducing VC interphase precipitation by the micro-alloying addition of $\mathrm{V}$. The refinement of the $\alpha$ grain size improves the ductility of steels without pronouncedly changing the strength level. The local strain distributions in the specimens plastically strained at the same level of $\sim 4 \%$ were quantified via DIC analysis based on SEM images, and the results are shown in Fig. 10b-e. The strain partitioning between $\alpha$ and martensite can be clearly observed in the coarse-grained V-free alloy, which is slightly weakened in its fine-grained counterpart. Such refinement of $\alpha$ grain size contributes to the improvement in post-uniform elongation because the strain localization at the $\alpha /$ martensite interface and resultant void formation occurring in common dual-phase steels can be suppressed. On the other hand, the strain partitioning is significantly mitigated irrespective of the $\alpha$ grain size in the Vadded alloy, due to the reduced difference in the strength of martensite and $\alpha$ with the dispersed nano-sized alloy carbides. As a result, the deformation in the $\mathrm{V}$-added low carbon steel becomes more homogenous, which should be the main reason for its excellent post-uniform elongation even at a high strength level. ${ }^{75}$

\section{SUMMARY AND FUTURE OUTLOOK}

The current understanding of the microstructure and properties of micro-alloyed low carbon steels strengthened by interphase precipitation of alloy carbides have been reviewed. The critical findings by the research group of the present authors can be summarized as:
1. A large deviation from the exact KurdjumovSachs orientation relationship of the $\alpha / \gamma$ interface with a relatively lower degree of coherency is necessary for interphase precipitation to occur.

2. The dispersion of alloy carbides formed by interphase precipitation is predominantly determined by the driving force for precipitation, which can be tuned by changing the transformation temperature and chemical composition.

3. The refinement in dispersion of interphase precipitation increases the strength without sacrificing the ductility, which is beneficial for the production of advanced high-strength steels with excellent mechanical properties.

Interphase precipitation in steels has already been widely studied for several decades. Toward the further improvement in mechanical properties via microstructural control of steels strengthened by interphase precipitation, many issues still remain to be solved in the future, from the viewpoint of the present authors. For example, (1) to maximize the strengthening potency of interphase precipitation, the processing conditions have to be optimized to enlarge its driving force by decreasing the ferrite transformation temperature, with the formation of Widmanstatten ferrite being suppressed; (2) in addition to the orientation relationship between ferrite and austenite, it is also necessary to clarify the influence of crystallographic interface orientations in order to control the dispersion of interphase precipitation via changing the crystallography of ferrite transformation; (3) the guidelines of alloy design with multiple addition of solute elements should be established for better microstructural control of interphase precipitation via tuning the interfacial segregation behaviors, the driving force for precipitation and interfacial energy between ferrite and alloy carbides; and (4) the strengthening mechanism of nano-sized alloy carbides needs to be refined with a higher degree of accuracy, and that of the presumably formed nanoclusters by interphase precipitation also needs to be clarified. We believe that this review can serve as a basis for research work on these challenging issues in the future.

\section{ACKNOWLEDGEMENTS}

This work was financially supported by Core Research for Evolutional Science and Technology (CREST) Basic Research Program entitled "Creation of Innovative Functions of Intelligent Materials on the Basis of Element Strategy" funded by Japan Science and Technology Agency (JST) (2011-2015), Grant-in-Aid for Young Scientists (A) No. 23686103 (2011-2012), Grant-in-Aid for JSPS Fellows No. 14J02944 (2014-2016), Grant-in-Aid for Scientific Research (A) No. 17H01330 (2017-2019) and Grantin-Aid for Scientific Research (B) No. 19H02473 (2019-2021) funded by Japan Society for the Promotion of Science (JSPS). The authors also 
acknowledge the Iron and Steel Institute of Japan for Research Promotion Grant (2019-2020), and Tohoku University - Tsinghua University Collaborative Research Fund (2020-2021). Mr. Kunio Shinbo in Institute for Materials Research, Tohoku University, is gratefully appreciated for his technical support in 3DAP measurements.

\section{CONFLICT OF INTEREST}

On behalf of all authors, the corresponding author states that there is no conflict of interest.

\section{OPEN ACCESS}

This article is licensed under a Creative Commons Attribution 4.0 International License, which permits use, sharing, adaptation, distribution and reproduction in any medium or format, as long as you give appropriate credit to the original author(s) and the source, provide a link to the Creative Commons licence, and indicate if changes were made. The images or other third party material in this article are included in the article's Creative Commons licence, unless indicated otherwise in a credit line to the material. If material is not included in the article's Creative Commons licence and your intended use is not permitted by statutory regulation or exceeds the permitted use, you will need to obtain permission directly from the copyright holder. To view a copy of this licence, visit $h$ ttp://creativecommons.org/licenses/by/4.0/.

\section{REFERENCE}

1. A.J. Ardell, Metall. Trans. A 16A, 2131. (1985).

2. T. Gladman, Mater. Sci. Technol. 15, 30. (1999).

3. N. Kamikawa, Y. Abe, G. Miyamoto, Y. Funakawa, and T. Furuhara, ISIJ Int. 54, 212. (2014).

4. E.C. Bain, Functions of the Alloying Elements in Steel (Cleveland, OH: ASM, 1939), pp. 228-312.

5. R.W.K. Honeycombe, Metall. Trans. A 7A, 915. (1976).

6. A.T. Davenport, F.G. Berry, and R.W.K. Honeycombe, Met. Sci. J. 2, 104. (1968).

7. N. Kamikawa, K. Sato, G. Miyamoto, M. Maruyama, N. Sekido, K. Tsuzaki, and T. Furuhara, Acta Mater. 83, 383. (2015).

8. Y. Funakawa, T. Shiozaki, K. Tomita, T. Yamamoto, and E. Maeda, ISIJ Int. 44, 1945. (2004).

9. J.-H. Jang, C.-H. Lee, Y.-U. Heo, and D.-W. Suh, Acta Mater. 60, 208. (2012).

10. J. Kim, J.-G. Jung, D.-H. Kim, and Y.-K. Lee, Acta Mater. 61, 7437. (2013)

11. S. Mukherjee, I.B. Timokhina, C. Zhu, S.P. Ringer, and P.D. Hodgson, Acta Mater. 61, 2521. (2013).

12. M.-Y. Chen, M. Goune, M. Verdier, Y. Brechet, and J.-R. Yang, Acta Mater. 64, 78. (2014).

13. J.-B. Seol, S.-H. Na, B. Gault, J.-E. Kim, J.-C. Han, C.-G. Park, and D. Raabe, Sci. Rep. 7, 42547. (2017).

14. Y.-Q. Wang, S.J. Clark, V. Janik, R.K. Heenan, D. Alba Venero, K. Yan, D.G. McCartney, S. Sridhar, and P.D. Lee, Acta Mater., 145, 84 (2018).

15. P. Gong, X.-G. Liu, A. Rijkenberg, and W.M. Rainforth, Acta Mater. 161, 374. (2018).

16. C. Ioannidou, Z. Arechabaleta, A. Navarro-Lopez, A. Rijkenberg, R.M. Dalgliesh, S. Kolling, V. Bliznuk, C. Pappas, J. Sietsma, A.A. van Well, and S.E. Offerman, Acta Mater. 181, 10. (2019).
17. J.-T. Wang, M. Welland, I. Bikmukhametov, M.K. Miller, P.D. Hodgson, and I. Timokhina, Scripta Mater. 160, 53. (2019).

18. N. Singh, G. Casillas, D. Wexler, C. Killmore, and E. Pereloma, Acta Mater. 201, 386. (2020).

19. C. Ioannidou, A. Navarro-Lopez, A. Rijkenberg, R.M. Dalgliesh, S. Koelling, C. Pappas, J. Sietsma, A.A. van Well, and S.E. Offerman, Acta Mater. 201, 217. (2020).

20. E. Pereloma, D. Cortie, N. Singh, G. Casillas, and F. Niessen, Mater. Res. Lett. 8, 341. (2020).

21. J.M. Gray, and R.B.G. Yeo, Trans. ASM 61, 255. (1968).

22. P.R. Howell, J.V. Bee, and R.W.K. Honeycombe, Metall. Trans. A 10A, 1213. (1979).

23. F.G. Berry, and R.W.K. Honeycombe, Metall. Trans. 1, 3279. (1970).

24. D.V, Edmonds and R.W.K. Honeycombe, J. Iron Steel Inst., 211, 209 (1973).

25. A. Barbacki, and R.W.K. Honeycombe, Metallography 9, 277. (1976).

26. T. Sakuma, and R.W.K. Honeycombe, Met. Sci. 18, 449 (1984).

27. T. Sakuma, and R.W.K. Honeycombe, Mater. Sci. Technol. 1, 351. (1985).

28. S. Freeman, and R.W.K. Honeycombe, Met. Sci. 11, 59. (1977).

29. A.D. Batte, and R.W.K. Honeycombe, J. Iron Steel Inst. 211, 284. (1973).

30. A.D. Batte, and R.W.K. Honeycombe, Met. Sci. J. 7, 160 (1973).

31. N.K. Balliger, and R.W.K. Honeycombe, Metall. Trans. A 11A, 421. (1980).

32. S.A. Parsons, and D.V. Edmonds, Mater. Sci. Technol. 3, 894. (1987).

33. K.R. Kinsman, E. Eichen, and H.I. Aaronson, Metall. Trans. A 6A, 303. (1975).

34. R.A. Ricks, and P.R. Howell, Acta Metall. 31, 853. (1983).

35. R.M. Smith, and D.P. Dunne, Mater. Forum 11, 166. (1988).

36. N.C. Law, S.A. Parsons, P.R. Howell, and D.V. Edmons, Mater. Sci. Technol. 3, 642. (1987).

37. G. Miyamoto, R. Hori, B. Poorganji, and T. Furuhara, Metall. Mater. Trans. A 44A, 3436. (2013).

38. R. Okamoto, A. Borgenstam, and J. Agren, Acta Mater. 58, 4783. (2010).

39. H.-W. Yen, P.-Y. Chen, C.-Y. Huang, and J.-R. Yang, Acta Mater. 59, 6264. (2011).

40. S. Zajac, T. Siwecki, W.B. Hutchinson, and R. Lagneborg, Mater. Sci. Forum 284-286, 295. (1998).

41. T. Murakami, H. Hatano, G. Miyamoto, and T. Furuhara, ISIJ Int. 52, 616. (2012).

42. A.T. Davenport, and R.W.K. Honeycombe, Proc. R. Soc. Lond. A 322, 191. (1971).

43. W.-J. Liu, Metall. Trans. A 24A, 2195. (1993).

44. J.A. Todd, P. Li, and S.M. Copley, Metall. Trans. A 19A, 2133. (1988).

45. J.A. Todd, and Y.-J. Su, Metall. Trans. A 20A, 1647. (1989).

46. M.-Y. Chen, M. Goune, M. Militzer, Y. Brechet, and J.-R. Yang, Metall. Mater. Trans. A 45A, 5351. (2014).

47. P.R. Rios, J. Mater. Sci. 30, 1872. (1995).

48. R. Lagneborg, and S. Zajac, Metall. Mater. Trans. A 31A, 1. (2000).

49. R. Okamoto, and J. Agren, Acta Mater. 58, 4791. (2010).

50. M. Goune, F. Danoix, J. Agren, Y. Brechet, C.R. Hutchinson, M. Militzer, G. Purdy, S. van der Zwaag, and H. Zurob, Mater. Sci. Eng. R 92, 1. (2015).

51. H.I. Aaronson, in Decomposition of Austenite by Diffusional Processes, ed. by V.F. Zackay, and H.I. Aaronson (New York: Inter- science, 1962), pp. 387-548.

52. Y.-J. Zhang, G. Miyamoto, K. Shino, and T. Furuhara, Scr, Mater., 69, 17 (2013).

53. G. Miyamoto, N. Iwata, N. Takayama, and T. Furuhara, Acta Mater. 58, 6393. (2010).

54. G. Spanos, and M.G. Hall, Metall. Mater. Trans. A 27A, 1519. (1996). 
55. T. Furuhara, H. Saito, G. Miyamoto, and T. Maki, Mater. Sci. Forum 654-656, 7. (2010).

56. Y.-J. Zhang, K. Shinbo, T. Ohmura, T. Suzuki, K. Tsuzaki, G. Miyamoto, and T. Furuhara, ISIJ Int. 58, 542. (2018).

57. T. Furuhara, and H.I. Aaronson, Scr. Metall. 22, 1635. (1988).

58. T. Furuhara, K. Oishi, and T. Maki, Metall. Mater. Trans. A 33A, 2327. (2002).

59. Y.-J. Zhang, G. Miyamoto, K. Shinbo, and T. Furuhara, Acta Mater. 128, 166. (2017).

60. H.-K. Dong, Y.-J. Zhang, G. Miyamoto, M. Inomoto, H. Chen, Z.-G. Yang, and T. Furuhara, Acta Mater., 215, 117081 (2021).

61. G. Miyamoto, K. Yokoyama, and T. Furuhara, Acta Mater. 177, 187. (2019).

62. H.-K. Dong, PhD Thesis, Tsinghua University (2021).

63. A.K. da Silva, R.D. Kamachali, D. Ponge, B. Gault, J. Neugebauer, and D. Raabe, Acta Mater. 168, 109. (2020).

64. Y.-J. Zhang, G. Miyamoto, K. Shinbo, T. Furuhara, T. Ohmura, T. Suzuki, and K. Tsuzaki, Acta Mater. 84, 375. (2015).

65. Y.-J. Zhang, G. Miyamoto, K. Shinbo, and T. Furuhara, Acta Mater. 186, 533. (2020).
66. Y.-J. Zhang, G. Miyamoto, K. Shinbo, and T. Furuhara, Metall. Mater. Trans. A 51A, 6149. (2020).

67. D.E. Coates, Metall. Trans. 3, 1203. (1972)

68. D.E. Coates, Metall. Trans. 4, 1077. (1973).

69. A. Hultgren, Trans. ASM 39, 915. (1947).

70. N. Takayama, G. Miyamoto, and T. Furuhara, Acta Mater. 60, 2387. (2012).

71. E. Hornbogen, and E.A. Starke Jr., Acta Metall. Mater. 41, 1. (1993).

72. M.F. Ashby, Philos. Mag. 21, 399. (1970).

73. H. Paruz, and D.V. Edmonds, Mater. Sci. Eng. A 117, 67. (1989).

74. N. Kamikawa, M. Hirohashi, Y. Sato, E. Chandiran, G. Miyamoto, and T. Furuhara, ISIJ Int. 55, 1781. (2015).

75. E. Chandiran, Y. Sato, N. Kamikawa, G. Miyamoto, and T. Furuhara, Metall. Mater. Trans. A 50A, 4111. (2019).

Publisher's Note Springer Nature remains neutral with regard to jurisdictional claims in published maps and institutional affiliations. 